\section{TCH-020 IMPROVING EFFICIENCY IN ELASTOMERIC PUMP FILLING USING DIANA ONCO PLUS, A SEMI-AUTOMATED COMPOUNDING DEVICE}

doi:10.1136/ejhpharm-2013-000276.211

'P Castell, 'MJ Ausina, 'R Sanz, $2 \mathrm{PI}$ Palomo-Jimenez, 'E Lopez-Briz, 'P Ramirez, 'M Ceita, 'A Chilet, 'A Estela, ' JL Poveda-Andres. 'Hospital La Fe, Pharmacy, Valencia, Spain; ${ }^{2}$ Hospira Prod. Ftcos. y Hosp. , Medical, Madrid, Spain

Background La Fe Universitario y Politécnico Hospital is a tertiarycare hospital with approximately 1000 beds serving a population of 210,000 people. The pharmacy department owns 4 vertical laminar flow hoods where more than 35,000 chemotherapy treatments, including the filling of 800 elastomeric pumps, are prepared per year. Purpose To compare both the time spent and the accuracy in the filling of elastomeric pumps (EPs) with fluorouracil by two different methods: DIANA ONCO-PLUS, a semi-automated compounding system (ICU Medical Europe), and the normal manual method used in the hospital's Chemotherapy Unit (CU). The secondary endpoint was to assess user satisfaction with the two methods.

Materials and Methods For 4 consecutive weeks, EPs were filled by trained nurses two days per week. The first day DIANA ONCOPLUS was used and the second day the EPs were filled manually. To avoid bias, every week a different nurse filled the EPs using both methods. Filling time was measured by a different nurse using a conventional chronograph and the accuracy was evaluated by weight of EP (before and after filling). Nurses' satisfaction was assessed by a questionnaire.

Results The filling of sixty-five EPs was evaluated. The filling mean time was $4.25 \mathrm{~min}$ with the manual method and $3.84 \mathrm{~min}$ with DIANA ONCO-PLUS $(p=0.008)$. If purge is considered, the mean time was $6.63 \mathrm{~min}$ and $5.52 \mathrm{~min}$ respectively $(\mathrm{p}<0.001)$. The mean relative error in the filling was $0.735 \%$ in manual method and $0.314 \%$ in DIANA method ( $p=0.006$ ) without any clinical relevance. There was no user-related variability. Nurses were very satisfied using DIANA for filling EP. They considered DIANA more comfortable and safe.

Conclusions DIANA ONCO-PLUS is a more efficient and accurate method to fill EPs than the manual method. The differences found were user-independent.

Acknowledgements The authors thank the Pharmacy Department of HUP La Fe, Nagore Castro, Loreto Gómez (Hospira PFH SL) and Roberto Zambrano (ICU Medical) for their collaboration in this study.

No conflict of interest

\section{TCH-021 INCORPORATION OF IL28B POLYMORPHISM DETERMINATION INTO THE SERVICES PORTFOLIO OF THE PHARMACY DEPARTMENT AND RESULTS OBTAINED}

doi:10.1136/ejhpharm-2013-000276.212

N Martinez Casanova, B Cancela Díez, C Garcia Collado, E Puerta Garcia, FJ Casado de Amezua, MA Calleja Hernández. Hospital Universitario Virgen de las Nieves, Pharmacy, Granada, Spain

Background Recent marketing authorizations for the first protease inhibitors for hepatitis $\mathrm{C}$ virus (HCV) have changed the management of chronic hepatitis $\mathrm{C}$ patients. However, it should be noted that the cost, number as well as the severity of adverse effects will increase. It is therefore reasonable to adopt criteria to ensure maximum efficiency and patient safety. IL-28B polymorphism is one of the factors associated with the treatment outcome and has been closely linked to interferon response.

Purpose To describe the implementation of the determination of the IL-28B polymorphism, rs12979860, and the results obtained, in order to personalise the treatment in HCV mono-infected patients in a tertiary hospital.

Materials and Methods We designed a standard form for HCV patients starting treatment with protease inhibitors. It includes several items that require clinical evaluation: viral load, HCV genotype, FibroScan and/or liver biopsy, response to previous treatment and polymorphism of the IL-28B genotype. Homozygous CC is the favourable genotype, predicting a good response. CT and TT genotypes are considered unfavourable.

The test was conducted in the pharmacogenetics area of the pharmacy department. To calculate the response time, we considered how long it takes to get the different responses.

The results were added to the hospital's electronic medical records programme for easy reference online.

Results A total of 26 genotypes was determined, of which 11 (42\%) were requested by the department of infectious diseases $(56 \%$ co-infected), 10 (38\%) by the hepatology department and 5 (18\%) by an external department. Results 15 (58\%) were CT, 8 (31\%) CC and $3(11 \%)$ TT. $100 \%$ of patients had a score of FibroScan $>$ $9.5 \mathrm{kPascal}$. The response for the tests was on average 3 to 7 days, with the limiting factor the sequencer availability.

Conclusions IL28B determination has been added to the hospital's services portfolio as a clinical assessment tool for the treatment of hepatitis $\mathrm{C}$, with a response time of 3-7 days.

No conflict of interest.

\section{TCH-022 INTRADIALYTIC CALCIPHYLAXIS IN RENAL PATIENTS. DEVELOPMENT OF AN INJECTABLE SOLUTION OF 25\% SODIUM THIOSULFATE FOR TREATMENT}

doi:10.1136/ejhpharm-2013-000276.213

C Gómez Peña, S Ruiz Fuentes, C García Fernandez, S Belda Rustarazo, C Fernandez López, C Medarde Caballero, A Caballero Romero, D Blanquez Martinez. Hospital San Cecilio, Farmacia Hospitalaria, Granada, Spain

Background Calciphylaxis (calcific uremic arteriolopathy) is the ischemic ulceration of the skin caused by the disseminated calcification of the subcutaneous tissue and small arteries as a consequence of hyperparathyroidism in uremic patients.

Purpose To describe the method of preparation and checking of an injectable solution of $25 \%$ sodium thiosulfate for the treatment of intradialytic calciphylaxis in renal patients.

Materials and Methods Sodium thiosulfate is an antioxidant, vasodilator and calcium chelator. The preparation process for the solution of $25 \%$ sodium thiosulfate is: Ingredients: Sodium thiosulfate pentahydrate: $25 \mathrm{~g}$, water for injection (WFI): qs $100 \mathrm{ml}$. Preparation: Weigh the amount of sodium thiosulfate in a sterile beaker Then, working in a horizontal laminar flow hood, boil WFI to eliminate $\mathrm{CO}_{2}$. Dissolve the thiosulfate in about $80 \mathrm{ml}$ of boiled water. Check that the $\mathrm{pH}$ of the solution is between 6 and 9.5, if it is not, adjust with $\mathrm{HCl}$ or $\mathrm{NaOH}$. Flush into a $100 \mathrm{ml}$ volumetric flask and make up to volume. Filter with a double 0.22 micron philtre. Finally pack with $50 \mathrm{ml}$ syringe into a sterile glass bottle and label.

Results The result is a solution of $100 \mathrm{ml}$ of $25 \%$ sodium thiosulfate, transparent, sterile and stable for 30 days in refrigerator. For OC a visual particulate sterility cheque is performed by sowing in aerobic and anaerobic cultures and a bubble point test to verify the integrity of the philtres.

Conclusions Proper preparation and checking of the $25 \%$ solution of sodium thiosulfate has guaranteed its parenteral administration is safe. The treatment is effective and well tolerated, helping patients and improving their quality of life.

No conflict of interest. 